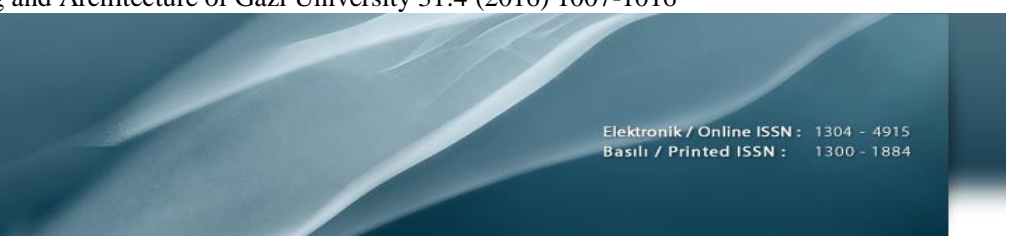

\title{
KOBİ'lere sağlanan desteklerin performans etkinlik sıralarının Promethee ve Oreste yöntemleri ile belirlenmesi enmesi
}

\author{
Mehmet Akif Yerlikaya, Feyzan Arıkan* \\ Gazi Üniversitesi, Mühendislik Fakültesi, Endüstri Mühendisliği Bölümü, 06570, Ankara, Türkiye
}

Ö N E Ç I K A N L A R

- $\quad$ KOBİ destek programlarının performans etkinlik sıralaması

- Çok kriterli karar verme ile performans değerlendirme

- $\quad$ Promethee ve Oreste yöntemlerinin bütünleşik kullanılması ile yeni bir etkinlik sıralaması öneri

Makale Bilgileri

Geliş: 06.10.2015

Kabul: 11.11.2015

DOI:

10.17341/gazimmfd.278456

Anahtar Kelimeler: Çok kriterli karar verme, çok ölçütlü karar verme, küçük ve orta büyüklükteki işletmeler, performans değerlendirme

\section{ÖZET}

Küçük ve orta büyüklükteki işletmeler (KOBİ) esnek ve dinamik yapıları nedeni ile ekonomide çok önemli rol oynarlar. Bu nedenle, ülkemizde işletmelerin \%99,8'ini oluşturan KOBİ'lerin hem yerli hem yabancı pazarda rekabet gücüne sahip birer işletme olmasına yönelik destekler oldukça önem kazanmaya başlamıştır. Bu çalışmada, KOBİ'lere sağlanan hibe nitelikli devlet destek programları için bir performans etkinlik sıralaması oluşturmak amaçlanmıştır. Bu amaç doğrultusunda, KOBI'lerin kendilerine en iyi faydayı sağlayacak desteği seçebilmeleri için desteklere ait performans değerlendirme problemi ele alınmıştır. Performans değerlendirme probleminin en etkin çözümü birden çok performans boyutunun, bir diğer deyişle birden çok kriterin varlığı dikkate alındığında mümkündür. Bu nedenle problem, çok kriterli karar verme yöntemlerinden PROMETHEE ve ORESTE kullanılarak çözümlenmiştir. Destek programlarının performans kriterleri için önem dereceleri AHP ile belirlenmiştir. PROMETHEE ve ORESTE yöntemlerinden elde edilen sonuçlar dikkate alınarak destekler için yeni bir etkinlik sırası önerilmiştir. Sınırlı sayıda destekten yararlanabilen KOBİ'lerin, destek başvurularında uygun seçimler yapabilmeleri için elde edilen etkinlik sırası yol gösterici nitelik taşımaktadır.

\section{Constructing the performance effectiveness order of SME supports programmes via Promethee and Oreste techniques}

\section{H I G H L I G H T S}

- Performance effectiveness order of SMEs' support programmes

- Performance evaluation by multiple criteria decision making

- A new efficiency order proposal by utilizing Promethee and Oreste methods in an integrated way

Article Info

Received: 06.10.2015

Accepted: 11.11.2015

DOI:

10.17341/gazimmfd.278456

Keywords:

Multiple criteria decision

making,

multi-attribute decision

making,

Small and medium sized enterprise,

performance evaluation

\section{ABSTRACT}

Small and medium-sized enterprises (SMEs) play a very significant role in economies because of their flexible and dynamic structures. Spesifically, in our country owing to their large share in total number of enterprises (99.8\%), SMEs have vital importance in Turkish Economy to accommodate the increased competition and the globalization of the marketplace. Accordingly, SMEs' support programmes have received increasing attention in both domestic and foreign markets. This study aims to construct a performance efficiency order for the govermental support programmes. Hence, a performance evaluation problem is considered to help SMEs in heading for the best beneficial governmental supports. Regarding multiple dimensions of performance as criteria is the key approach to obtain the efficient solutions to the performance evaluation problem which is a multiple criteria decision making problem. Therefore, in this study PROMETHEE and ORESTE techniques are utilized. The relative importances of the SMEs'performance criteria are determined by AHP. Taking the results obtained from PROMETHEE and ORESTE techniques into account, a new effectiveness order for the supports is suggested. The obtained effectiveness order leads the SMEs that can utilize only the limited number of supports, in making the appropriate support choices.

\footnotetext{
* Sorumlu Yazar/Corresponding author: farikan@gazi.edu.tr / Tel: +90 3125823810
} 


\section{GİRIŞ̧ (INTRODUCTION)}

KOBİ'lerin, hem sosyal hem de ekonomik kalkınmadaki önemini fark eden pek çok ülke, bu işletmelerin etkinliğini arttırabilmek amacıyla çeşitli destek programları oluşturmaktadır. Avrupa Birliği (AB)'de; bu işletmeler üzerine önemle eğilmekte, istihdam, büyüme ve rekabet gücü üzerindeki katkılarını geliştirebilmek için ilgili politikalarda KOBI'lere öncelik tanımaktadır. AB uyum sürecinde, Türk KOBİ'leri; üretim, satış, pazarlama, ihracat ve kalite alanlarında darboğaz ve uyum sorunlarıyla karşı karşıya kalmaktadır. Bu nedenle, KOBI'lerin rekabet güçlerini geliştirmeye yönelik politika ve stratejilerin belirlenmesi ülkemiz ekonomisi açısından büyük önem taşımaktadır. Bu süreçte, KOBİ'lerin teknolojik gelişmeleri yakından takip etmeleri, teknoloji transferi ya da araştırmateknoloji geliştirme faaliyetlerine ve kaliteye ağırlık vermeleri gereklidir. Ülkemizde, tarihsel süreç içerisinde Cumhuriyet öncesi ve sonrası yasal düzenlemelerle teşvik konusunda pek çok çalışma yapılmıştır [1]. KOBİ'lerin desteklenmesini amaçlayan programlar, 1980'li yıllardan itibaren daha önemli bir hale gelmiş ve 1990'lı yılların başından itibaren bu amaca hizmet eden Küçük ve Orta Ölçekli İşletmeleri Geliştirme ve Destekleme İdaresi (KOSGEB) ve Türkiye Teknoloji Geliştirme Vakfı (TTGV) gibi yapıların kurulmasıyla hız kazanmıştır. 2000'li yıllarda ise desteklerin ve uygulayıcı kuruluşların sayısında önemli artışlar yaşanmıştır. Her ne kadar büyük kısmı doğrudan KOBİ'ler hedef alınarak tasarlanmamış olsa da, ülkemizde farklı kurumlarca yürütülen ve özel sektör işletmelerine açık olan pek çok destek mevcuttur. Desteklerin çeşitleri ve sınıflandırılmasına [2] ve [3]'de yer verilmiştir. KOBİ'lere sağlanan destek programları temel olarak hibe (geri ödemesiz) ve kredi (geri ödemeli) olmak üzere iki sınıfa ayrılabilir. KOBI'lere destek sağlayan kurumlar ise devlete bağl1 kurumlar ve özel kurumlar olmak üzere iki türlüdür. $\mathrm{Bu}$ çalışmada, hibe nitelikli devlet destek programları dikkate alınmıştır. KOBİ'lerin destek programlarından en iyi şekilde yararlanması ve performanslarını olumlu yönde etkileyecek destek çeşitlerinin belirlenmesi, hem KOBİ'ler açısından hem de desteği sağlayan kurum ve kuruluşlar açısından önem arz etmektedir. KOBİ'lerin yararlandığı desteklerden beklenen etkiye ve verime ulaşamamasının sebeplerinin başında, bilimsel temele dayanan bir planlama yapılmaması gelmektedir [4]. Bu eksikliği giderebilmek için, en etkin destek programlarının belirlenmesi problemi bu çalışmada ele alınmış ve etkin bir çözüm önerisi getirilmesi amaçlanmıştır. Geliştirilen çözümün etkinliği, problemin gerçek yaşamdaki bütün özelliklerinin göz ardı edilmeden dikkate alınması ile mümkündür. Performans değerlendirme problemi için de kantitatif ve kalitatif birden çok ölçütün dikkate alınması, problemin gerçekçi modellenmesi için kaçınılmazdır. Bu çalışma, amacı doğrultusunda; geleneksel örgütsel performans değerlendirme ölçütlerinden çok, KOBİlere sağlanan desteklerin performans üzerindeki etkisini açığa çıkaran birden çok ölçütü dikkate alan bir karar problemini dikkate almaktadır. $\mathrm{Bu}$ karar probleminin en etkin çözümünü hedefleyen çalışmanın, akış planı şu şekildedir: İkinci bölümde, çalışmanın literatüre katkısını ortaya koyan detaylı bir literatür araştırmasına yer verilmiştir. Üçüncü bölümde, yararlanılan çok ölçütlü karar verme (ÇÖKV) teknikleri açıklanmıştır. Dördüncü bölüm, uygulama çalışmasını kapsamaktadır. Uygulamanın ilk aşamasında, iki bölümden oluşan bir anket çalışması ile veri toplanmıştır. Anketin ilk bölümü KOBİ’lere sağlanan desteklerin performans üzerindeki etkisini açığa çıkaran toplam on ölçüt için veri toplamak üzere düzenlenmiştir. Elde edilen veriler AHP yöntemine girdi olarak kullanılmış ve kriter ağırlıkları belirlenmiştir. Anketin ikinci bölümünde ise her bir desteğin dikkate alınan ölçütler nazarında değerlendirebilmek için veri toplanmıştır. Her iki bölümden elde edilen veriler PROMETHEE ve ORESTE yöntemleri için girdi oluşturmuştur. Beşinci bölümde, çalışmanın sonuçları ve geleceğe yönelik çalışmalar belirtilmiştir.

\section{LITERATÜR ARAŞTIRMASI (LITERATURE REVIEW)}

Literatürde örgütsel performans değerlendirme ve KOBİ performans değerlendirme ile ilgili pek çok çalışma mevcuttur [5]. Bu çalışmalar, içerik açısından dört ana başlıkta incelenebilir: (1) KOBİ örgütsel performansının değerlendirilmesi, (2) KOBİ performansını etkileyen faktörlerin belirlenmesi, (3) KOBİ'lerin gelişimine yönelik ihtiyaç duyulan desteklerin ve teşviklerin tespiti, (4) KOBİ faaliyetleri ve performanslara desteklerin etkisini inceleyen çalışmalardan oluşmaktadır. Bunlar içerisinde, KOBİ performans değerlendirmesini ÇÖKV teknikleri ile gerçekleştiren az sayıda SCI çalışma, Voulgaris vd. [6], Vincent vd. [7], Ahmed ve Qui [8], Tsai ve Chuo [9], Tsai ve Kuo'ya [10] aittir. KOBİ'lere sağlanan kamusal desteklerin KOBI performansina etkisini inceleyen çalışmalar Maden [12] tarafından araştırılmıştır. Bu çalışmalarda, destek programlarının; üretim miktarı, satış hacmi gibi geleneksel KOBİ performans kriterleri üzerine dönemsel etkilerinin araştırıldığ 1 istatistiksel analiz teknikleri kullanılmıştır. Ağırlıklı olarak kullanılan yöntem, regresyon analizidir. Regresyon analizinde, "bağımlı ve bağımsız değişken" olarak seçilen sırasıyla "destekler ve performans ölçütleri” arasında, belirli bir anlamlılık düzeyinde ilişki var olup olmadığı ve ilişkinin yönü konusunda bilimsel bulgulara ulaşılmıştır. Literatürde destek programlarının Türkiye KOBİ'lerinin performansına etkisini inceleyen sadece üç çalışma ([11-13]) mevcuttur. Özçelik ve Taymaz [11], Maden [12] ve Erdil ve Kalkan'a [13] aittir. Bu çalışmalar da destek programları ve dikkate aldıkları performans ölçütlerinin ilişkilerini ortaya koymuş fakat Maden [12]'in belirttiği diğer çalışmalarda da olduğu gibi destek programları için bir önem sırası belirlenmemiştir. Mevcut çalışmalardan Özçelik ve Taymaz [11], 1993-2001 dönemi için sadece Türkiye Teknoloji Geliştirme Vakfi (TTGV) ve TÜBİTAK araştırma geliştirme desteğinin; sektörel büyüme oranı, kalifiye çalışan payı, göreli işçi verimliliği, reel çıktı vb. tanımlayıcı istatistikler kullanarak Türkiye genelinde firmalar 
üzerindeki etkisini araştırmıştır. Özçelik ve Taymaz [11] çalışmalarında sadece araştırma geliştirme desteğini dikkate almışlardır. Türkiye'de devlet araştırma geliştirme desteklerinin özel sektör yatırımları üzerinde belirgin ve pozitif bir etkiye sahip olduğunu belirlemişlerdir. Maden [12], ve Erdil ve Kalkan [13] ise birden çok destek programını dikkate almışlardır. Maden [12], KOSGEB genel destek programı kapsamında sunulan desteklerin göller bölgesinde faaliyet gösteren KOBİ'lerin performans1 üzerindeki etkilerini ortaya koymuştur. Bu kapsamda 20082011 yılları arasinda Isparta ve Burdur illerinde faaliyet gösteren ve KOSGEB genel destek programından yararlanmış olan KOBİ'ler ve bu KOBİ'lerle aynı bölgede faaliyet gösteren sektör, ölçek ve firma yaşı itibariyle aynı özellikleri taşıyan ve hiçbir destek programından faydalanmamış olan KOBI'ler incelenmiştir. Araştırma için destek alan ve almayan KOBI'ler üzerine Logit ve Tobit istatistiksel analiz tekniğini kullanmıştır. Maden [12] çalışmasında dikkate aldığı destekler, tanıtım, nitelikli eleman, yurtiçi fuar, yurtdışı iş gezisi, test analiz kalibrasyon, belgelendirme destekleridir. Firma performansı ise istihdam, ürün çeşidi sayısı, üretim miktarı, satış hacmi, müşteri sayısı ve ürün kalitesi olarak altı ölçüt ile tanımlanmıştır. Elde edilen bulgular genel olarak değerlendirildiğinde sağlanan desteklerin istihdam, üretim miktarı ve satış hacmi üzerinde anlamlı ve pozitif etkilerinin olduğu gözlenmiştir. Erdil ve Kalkan [13], çalışmalarında KOBI'lere sağlanan desteklerin örgütsel performansa etkisini bulmak amaciyla Ankara ve Konya illerinde faaliyet gösteren KOBİ'ler üzerine bir anket çalışması uygulamışlardır. Elde edilen verilerle SPSS programı kullanarak regresyon ve varyans analizini yapmışlardır. Erdil ve Kalkan'ın [13] çalışmalarında dikkate aldıkları destekler; teknoloji, eğitim, finans, makine-teçhizat, pazarlama ve danışmanlıktır. Firma performans1 ise ürün kalitesi, ürün yeniliği ve karlılık olarak üç ölçüt ile tanımlanmıştır. Pazarlama desteğinin doğrudan karlılı̆̆ 1 etkilediğini gözlemlemiştir. Teknoloji ve eğitim desteği ile ürün yeniliği arasında pozitif ilişki ortaya çıkmıştır. Eğitim desteğinin; ürün kalitesi, ürün yeniliği ve karlılık üzerinde güçlü bir etkisi olduğunu ortaya koymuşlardır. Finans ve makina teçhizat desteğinin ise performans üzerinde etkisi olmadığı sonucuna ulaşmışlar ve bu durumu örnek kitleyi oluşturan firmaların ilgili destekleri yeterince kullanamamış olması olasılığı ile açıklamışlardır.

Yukarıda belirtilen çalışmalar ışı̆̆ında, literatürde; destek programlarını KOBİ performansına etkisini ÇÖKV tekniklerini dikkate alarak inceleyen bir çalışma mevcut değildir. $\mathrm{Bu}$ çalışma, temel amacı itibariyle; destek programlarının KOBI performansına etkisini PROMETHEE ve ORESTE teknikleri ile birden çok ölçütü dikkate alarak incelemesi sebebiyle literatüre katk1 sağlamaktadır. Mevcut çalışmayı diğerlerinden ayıran özgünlük ise, dönemsel bir istatistiksel analiz yerine, destek programlarından son 10 yıl içerisinde faydalanmış KOBI'lerin uzman bilgilerine dayanarak birden çok performans ölçütü nazarında destek programları için bir önem sıralaması oluşturmaktır. Böylece, KOBİ'lerin sınırlı sayıda yararlanabildiği destekler için en uygun başvuruları yapmalarında yol gösterici nitelikte sonuçlar arz etmektir. $\mathrm{Bu}$ anlamda mevcut çalışma, önceki çalışmalardan elde edilen, "destekler ve KOBİ performansı arasındaki anlamlı ilişkilerin" bilgisi ışığında, hangi desteklerin daha faydalı olacağını araştırmayı hedefleyerek sonraki adımı gerçekleştirmektedir. PROMETHEE Yöntemi için gerekli kriter ağılıkları AHP yöntemi ile hesaplanmıştır. İlgili kriter ağırlıkları ORESTE yönteminin ilk adımı olan zayıf sıranın oluşturulmasında da kullanılmıştır. Ayrıca, söz konusu iki yöntemden elde edilen sonuçlar bütünleşik olarak dikkate alınarak, destekler için yeni bir etkinlik sırası önerilmiştir. Önerilen sıralama, ülkemizin ekonomik kalkınmasında stratejik öneme sahip KOBİ'lerin performanslarını arttırabilmeleri için en uygun başvuruları yapmalarında yol gösterici nitelikte olması bakımından önem arz etmektedir. Elde edilen sıralamanın, ayrıca destekleri sağlayan kuruluşlara, desteklerin yapısal düzenlemesi ve bütçe planlanması açısından yardımcı olacağı düşünülmektedir.

Literatürde çok kriterli karar verme (ÇKKV) problemlerinin çözümü için pek çok yaklaşım mevcuttur. "ÇKKV", çok amaçlı karar verme ve ÇÖKV modelleri ve tekniklerinin tümü için genel ve bilimsel bir isim olarak kullanılmaktadır [14-17]. Literatürde ölçüt ve kriter kelimeleri sıklıkla birbiri yerine kullanılageldiğinden ÇÖK teknikleri, ÇKK teknikleri olarak da adlandırılmaktadır. Bu çalışmada da ölçüt ve kriter kelimeleri değiş̧imli olarak kullanılmıştır. $\mathrm{Bu}$ çalışmada, KOBİ yöneticilerinin uzmanlıkları, bilgileri, tecrübeleri ve tercihlerini ifade etmesine imkan tanıyan sübjektif kriter ağırlıkları, probleme yön veren önemli bir bilgi kaynağı olduğundan AHP $[18,19]$ yönteminden faydalanılarak gerçekçi sayısal verilere dönüştürülmüştür. Destek programlarının sıralanmasında ise, siralama tekniklerinden PROMETHEE, kıyaslanamazlık problemini aşabildiği için [18] tercih edilmiştir. Diğer taraftan, anketin ikinci bölümüne ait veriler 1-5 ölçeğinde sayısal veriler olması dolayısıyla, fayda fonksiyonları kullanılmaksızın tercih siralaması oluşturabilmek ve PROMETHEE sıralama sonuçları ile kıyaslayabilmek için ORESTE yöntemi [20] çalışmaya dahil edilmiştir. Çalışmanın ilerleyen aşamasında ise her iki yöntemin sonuçlarından faydalanılarak yeni bir sıralama önerisi geliştirilmiştir.

\section{METODOLOJİ (METODOLOGY)}

\subsection{Analitik Hiyerarşi Proses (Analytical Hierarchy Process)}

1965 y1lında L. Thomas Saaty [21] tarafından geliştirilen AHP, literatürde yaygın kullanıma sahip ÇKKV tekniğidir. AHP, objektif ve sübjektif kriterleri ikili karşılaştırma yaparak ölçen ve bu kriterlerin birbirlerine göre önceliklerini bularak göreli önem sıralarını (ağırlıklarını) belirleyen bir karar verme tekniğidir. AHP'nin 5 temel adımı aşağıdaki gibidir: 
Adım 1. Problem ortaya konur, hiyerarşide en üstte yer alacak hedef belirlenir.

Adım 2. Amaç, kriterler, alt kriterler ve alternatifleri içeren hiyerarşi oluşturulur.

Adım 3. İkili karşılaştırma matrisi oluşturulur.

Adım 4. Göreli önem vektörü (ağırlık vektörü) bulunur.

Adım 5. Tutarlılık oranı hesaplanır. Tutarlılık durumunda karar verilir. Tutarlı olmama durumunda ikili karşılaştırmalar tekrar gözden geçirilerek işlemler tekrarlanır.

\subsection{PROMETHEE Yöntemi (The PROMETHEE Method)}

PROMETHEE (Preference Ranking Organization Method for Enrrichment Evaluations) yöntemi, Brans vd. [22] tarafından 1982 yılında geliştirilmiş ÇÖKV tekniğidir. PROMETHEE Yöntemi, PROMETHEE-I (kısmi sıralama) ve PROMETHEE-II (tam siralama) olarak bilinmektedir. Bunların haricinde PROMETHEE III, IV, V ve VI gibi farklı versiyonları da bulunmaktadır. PROMETHEE Yönteminin uygulanabilmesi için iki tip bilgi gereklidir. Birincisi kriterlerin göreli önem derecesi (ağırlıkları), ikincisi ise karar vericinin tercihine göre alternatiflerin kriterlere ilişkin değerleridir. Karar vericinin tercihi, 6 farklı tercih fonksiyonundan ((I). Olağan, (II). U-tipi, (III). V-Tipi, (IV). Basamaklı, (V). Farksızlık alanlı V-Tipi, ve (VI). Gaussian) uygun olanlar kullanılarak tanımlanır [23].

PROMETHEE Yöntemi 5 adımdan oluşmaktadır [22]:

1. Alternatifler kümesi, alternatifin her bir kritere ilişkin değeri ve her bir kriterin göreli ağırlığı belirlenir.

2. Alternatif çiftleri için kriter bazında uygun ortak tercih fonksiyonları belirlenir.

3. Her alternatif çifti için tercih indeksleri belirlenir.

4. PROMETHEE I ile kismi siralama belirlenir. Alternatifler için pozitif ve negatif üstünlükler belirlenir.

5. PROMETHEE II ile alternatifler için tam sıralama belirlenir. Her bir alternatif için hesaplanan net üstünlük değerleri ve bütün alternatifler için tam sıralama belirlenir.

\subsection{ORESTE Yöntemi (The ORESTE Method)}

Oreste (Organisation, rangement et synthèse de données relationnelles -in French), ELECTRE yöntemine bir alternatif olarak 1979'da M. Roubens tarafindan geliştirilmiş bir ÇKKV metodudur [20]. ORESTE Yöntemi, "aksiyon" olarak da adlandırılan alternatiflerin her bir kritere göre diğer bir alternatife üstünlüğünün belirlendiği bir sıralama yöntemidir. ORESTE Yöntemi; ORESTE-I tam sıralama ve ORESTE-II uyuşmazlık analizi olarak iki kısımdan oluşur [20, 24]:

ORESTE-I Yöntemi 3 aşamadan oluşmaktadır:

1. Alternatiflerin ve Kriterlerin Belirlenmesi, zayıf sira ve Besson sırası: Karar verici tarafindan belirlenen Farksızlık (I) ve Tercih (P) ilişkilerine uygun olarak, kriterler ve her bir kriter nazarında alternatifler büyükten küçüğe sıralanarak "zayıf sırası" oluşturulur. Daha sonra, M. Besson tarafindan önerilen ve kendi ismi ile anılan sira belirlenir. İki veya ikiden fazla her bir kriter ve her bir kriter nazarında alternatif değerlerinin eşit çıkması durumunda bu alternatif veya kriterlerin "Besson" sira değerleri aritmetik ortalama formülü ile hesaplanır.

2. Alternatiflerin Projeksiyon Uzaklıklarının Hesaplanması: Önceki adımdan elde edilen sıra değerleri dikkate alınır ve keyfi olarak bir başlangıç noktası belirlenir. Bu başlangıç noktasına göre, her bir alternatife ait kriterler nazarında projeksiyon uzaklıkları olarak adlandırılan sayısal değerler hesaplanır. Kriterin önem ilişkisini dikkate alarak alternatifleri karşılaştırmak için kullanılan bu mesafeler, doğrusal ortogonal, doğrusal eğimli ve doğrusal olmayan projeksiyon formülleri [20] ile hesaplanır.

3. Tüm Projeksiyonların Dizilimi ve Global Sıra: Bir önceki adımda hesaplanan uzaklık değerlerine göre alternatifler küçükten büyüğe doğru sıralanır ve bulundukları sıra sayı değeri dikkate alınarak yeni Besson sıra değerleri hesaplanıp atanır. Sıra değeri aynı olan kriter ya da alternatiflerin sıra değerlerinin aritmetik ortalaması alınarak yeni bir sıra değeri belirlenir. Global sıralar, her bir alternatif için yeni Besson sıra değerleri toplamı alınmak suretiyle elde edilir.

ORESTE II, “farksız" ve "kıyaslanamaz" alternatifleri teşhis etmek amacıyla kullanılır. "Farksızlık ve uyuşmazlık analizi” olarak da bilinir. ORESTE-I yönteminin 3 . aşamasında elde edilen Besson sıra değerleri dikkate alınarak alternatiflerin diğer alternatiflere Tercih Yoğunluğu [20] hesaplanır ve normalize edilir. Elde edilen normalize değerler üç eşik değeri ile kıyaslanarak alternatiflerin birbirleri için Farksız (I), Karșılaștırılamaz (R) ve Tercih (P) edilir olup olmadığ 1 tespit edilir. Pastijn ve Leysen'e [20] göre üç eşik $\left(\beta, C^{*}, \gamma\right)$, n tane alternatif ve $\mathrm{k}$ tane kriter olmak üzere alternatif ve kriter sayısını temel alan formüller ile hesaplanır ve tanımları sırasıyla şöyledir: Eşik $\beta \leq[1 /(n-1) k] \rightarrow$ Bir alternatifin diğer bir alternatife üstünlüğü kesin olabilecek minimum değerin baz alındığı bir eşiktir. Eşik $C^{*} \leq[1 /(2(n-1))] \rightarrow$ Bir alternatifin diğer bir alternatife eşit olabileceği minimum durum ile Farksızlık (I) ve Karşılaştııılamaz (R) arasındaki ilişkiyi veren bir eşiktir. Eşik $\gamma<[4 p /(k-2 p)] \rightarrow$ Bir değerin başka bir değere yakınlı derecesi ile Tercih (P) ve Karşılaştırılamaz (R) arasındaki ilişkiyi veren bir eşiktir. Eşik $\gamma$ formülündeki $\mathrm{p}$, tek kriterli karar matrisinde 0,5 ve çift kriterli karar matrisinde 1 olarak alınmaktadır [5].

\section{SONUÇLAR VE TARTIŞMALAR (RESULTS AND DISCUSSIONS)}

Kalkan [2], destek programlarını altı ana kategoriye, Tezyetiş [3] ise sekiz farklı kategoriye ayırmıştır. Bu çalışmada değerlendirilecek olan hibe niteliğindeki destek programları, Kalkan [2] ve Tezyetiş'in [3] yapmış olduğu çalışmalar dikkate alınarak, toplam dokuz ana sınıfa ayrılmıştır. Bunlar sırasıyla, Araştırma ve Geliştirme Desteği (AGD), Teknoloji Desteği (TD), Eğitim Desteği 
(ED), Pazarlama Desteği (PD), Makine ve Teçhizat Desteği (MTD), Kalite Gelişim Desteği (KGD), Danışmanlık Desteği (DD), İnsan Kaynakları Desteği (İKD) ve Finansal Destek (FD)'tir. Destek programlarının tanımları şunlardır: Makine-Teçhizat Desteği: Yeni teknoloji kullanımı sağlayacak makine ve teçhizat yenilenmesinde maliyetin bir bölümünün sübvanse edilmesini ifade etmektedir. Ortak kullanım atölyeleri, laboratuvarları, makine-ekipman ve laboratuvar cihazlarının alımı için sağlanan destek programıdır. Pazarlama Desteği: KOBİlerin yeni pazarlara girebilme, ürünlerini sadece yerel pazarlarda değil yurt dışı pazarlarda da satabilme konusunda küçük ölçekli olmaktan kaynaklanan dezavantajlarını gidermek amacıyla ve sistematik olarak pazar araştırması yapmalarını teşvik etmek üzere oluşturulmuş bir destek programıdır. Danışmanlık Desteği: KOBİ'lerin hammadde seçiminden ürün pazarlamasına kadar her safhada karşılaştıkları sorunların çözümüne yönelik olarak; ürün kalitesinin geliştirilmesi, maliyetlerin düşürülmesi, kalite yönetim sisteminin kurulması, yönetim danışmanlığı gibi konularda danışmanlık hizmetlerinden yararlanmasını teşvik eden destek programlarıdır. Eğitim Desteği: KOBİ'lerde çalışanların teknik, yönetim, kalite, teknoloji, mali ve mevzuat konularında kendilerini geliştirmeleri için eğitim programları, kurslar, konferans ve panellere katılım nitelikli işgücünü yetiştirmek amacına hizmet eden destek programlarını kapsamaktadır. Finans Desteği: KOBI'lerin öz kaynak ve işletme sermayesi yetersizliği, kredi tür ve miktarının yetersizliği, kredi koşullarının KOBI'ler için çok ağır olması gibi finans sorunlarını azaltmak amacına yönelik destek programıdır. Araştırma-Geliştirme Desteği: KOBİ'ler yeni ürün, yeni süreç ve yeni hizmet üretmesi ve ticarileşmesi için araştırma, geliştirme ve uygulama alanlarında da desteklerine yönelik programlardır. Insan Kaynakları Desteği: KOBİ'lerin büyümesini desteklemek, istihdamı geliştirmek ve işçi alımına teşvik etmek için KOBİ'lere kısmi veya tam maaş olarak sağlanan personel desteklerini kapsamaktadır. Kalite Gelişim Desteği: KOBİ'lere kalite yönetim sistemleri ve gerekli ulusal, uluslararası belge veya sertifikaların alınması, konusunda sağlanan destek programlarıdır. Teknoloji Desteği: KOBI'ler daha kaliteli, daha güvenilir ürünler üretmesi veya daha iyi hizmet verebilmesi, iletişim ağının gelişmesi ve modern çağa ayak uydurabilmesi açısından teknolojik olarak desteklenmesine teşvik programlarını kapsamaktadır.

KOBİlere sağlanan desteklerin KOBİ performansına etkisini ortaya çıkaracak olan toplam on adet kriter, KOSGEB destek biriminde görevli 3 kişilik uzman ekibin yardımıyla belirlenmiştir. Belirlenen kriterler örgütsel performans kriterleri ve proje kriterleri olmak üzere iki türlüdür. Örgütsel performans kriterleri; Girişimcilik (G), Sanayileşme (S), Yerli Pazardaki Satışlar (Y), Ürün Kalitesi ve Gelişimi (Ü), Pazarlama (P), Yeni Ürün Dizaynı (YE), Bölgesel Gelişim (B) ve İhracat (I)'tır. Proje kriterleri ise; Proje Süresi (PS) ve Proje Bütçesi (PB)'dir. Kriter tanımları birbirinden bağımsız birbirini kapsamayacak şekilde yapılmıştır [5].

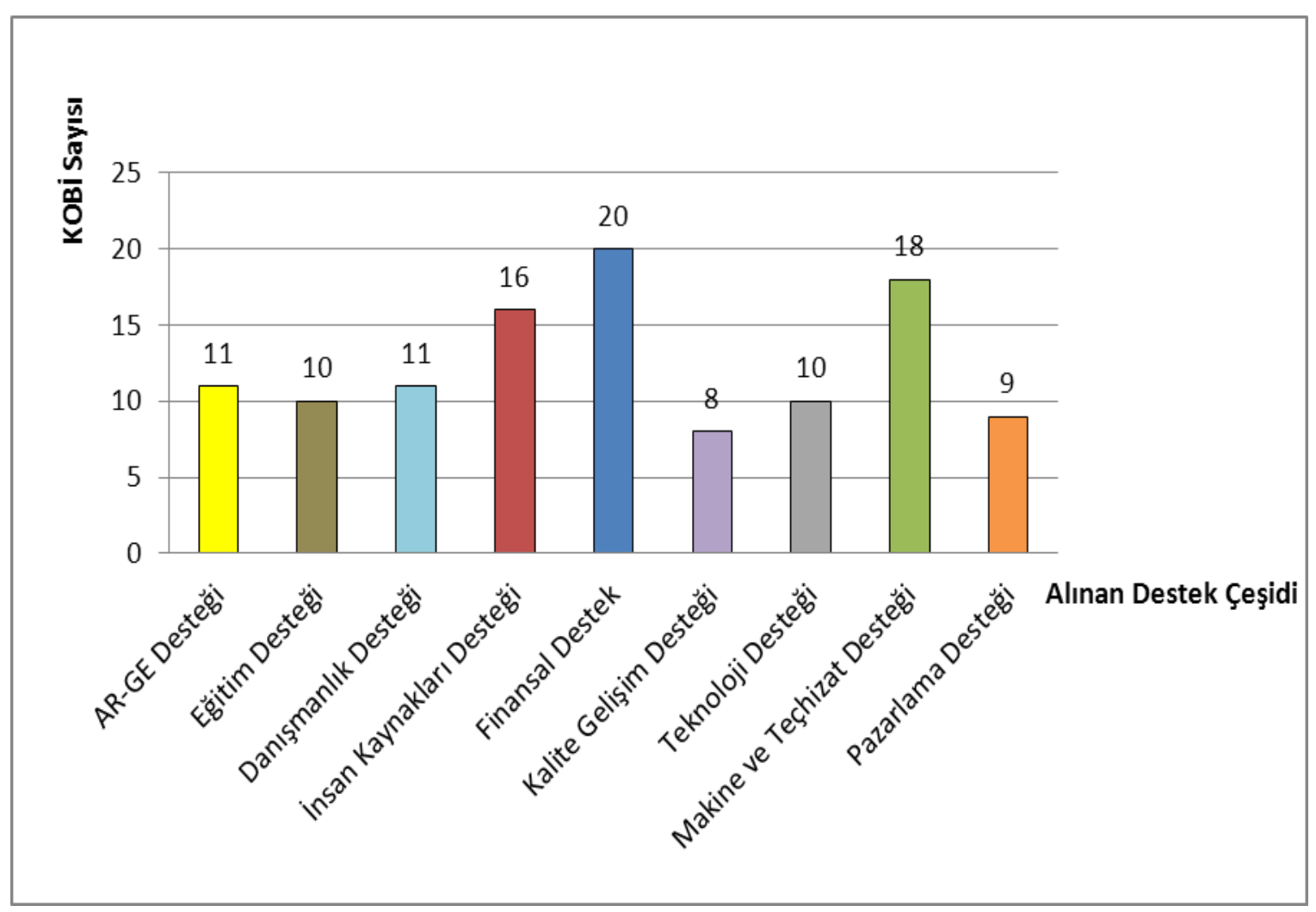

Şekil 1. KOBİ'lerin son 10 yılda almış oldukları desteklerin dağılımları (Frequency distribution of the support programs that SMEs' utilized last 10 years) 
Tablo 1. Karar matrisi (Decision matrix)

\begin{tabular}{lllllllllll}
\hline Kriterler $\rightarrow$ & $\mathrm{G}$ & $\mathrm{S}$ & $\mathrm{Y}$ & $\ddot{U}$ & $\mathrm{P}$ & $\mathrm{YE}$ & $\mathrm{B}$ & $\mathrm{I}$ & $\mathrm{PS}$ & $\mathrm{PB}$ \\
\hline $\begin{array}{l}\text { Kriter } \\
\text { Ağırlıkları } \rightarrow\end{array}$ & 0,093 & 0,085 & 0,152 & 0,175 & 0,199 & 0,135 & 0,076 & 0,059 & 0,013 & 0,012 \\
$\begin{array}{l}\text { Alternatifler } \downarrow \\
\text { AGD }\end{array}$ & & & & & & & & & \\
DD & 3,91 & 3,82 & 3,91 & 4,36 & 3,36 & 3,91 & 3,82 & 2,55 & 18 & 150000 \\
ED & 3,91 & 3,27 & 3,73 & 3,82 & 3,64 & 2,45 & 3,27 & 2,45 & 12 & 15000 \\
FD & 3,00 & 3,00 & 3,20 & 3,50 & 3,80 & 2,50 & 3,00 & 1,70 & 12 & 10000 \\
IKD & 3,15 & 3,30 & 3,60 & 3,45 & 3,75 & 3,05 & 3,45 & 2,35 & 24 & 25000 \\
KGD & 2,88 & 3,25 & 3,50 & 3,25 & 4,00 & 2,81 & 3,37 & 2,13 & 48 & 100000 \\
MTD & 3,75 & 3,00 & 3,75 & 4,13 & 3,50 & 3,75 & 3,50 & 3,25 & 24 & 25000 \\
PD & 3,06 & 3,67 & 3,78 & 3,67 & 3,28 & 3,28 & 3,61 & 2,61 & 36 & 75000 \\
TD & 3,89 & 3,33 & 4,00 & 3,67 & 4,22 & 2,89 & 3,78 & 3,00 & 36 & 45000 \\
& 3,40 & 3,60 & 4,00 & 3,50 & 4,00 & 2,50 & 3,40 & 2,70 & 12 & 25000 \\
\hline
\end{tabular}

\subsection{Anket Çallşması (Survey Study)}

Araştırma kapsamında, 18 farklı sektör ve 4 bölgede faaliyet gösteren, önceden hibe nitelikli devlet desteği almış 50 KOBİ dikkate alınmıştır. Anket uygulaması, KOBİ yöneticileri ile 2014 Şubat-Haziran döneminde 42'si yüz yüze 8 tanesi internet ortamında gerçekleştirilmiştir. Anketin uygulandığı 50 KOBİ'nin destek aldığı kurumlar ve son 10 yılda almış oldukları destek programları sorgulanmış elde edilen veriler frekans dağılımlarıyla değerlendirilmiştir (Şekil 1). Anketin tüm sorularında, belirsizlikleri engellemek için kapalı uçlu soru tipi kullanılmıştır. Yöneticilerin, yanıt şıkkında verilen cetvelden kendilerine en uygun olan değeri seçmeleri için ölçekli yanıtlar düzenlenmiştir. Anketin ilk bölümü, KOBİ'lere sağlanan desteklerin performans üzerindeki etkisini ortaya çıkaran kriterler için ikili karşılaştırma matrislerinin elde edilmesi için düzenlenmiștir. Anketin ikinci bölümünde ise, her bir destek programını, dikkate alınan kriterler nazarında değerlendirebilmek için veri toplanmıştır. Belirlenen kriterlerden örgütsel performans kriterleri uzman görüşlerinden elde edilen sübjektif nitel veriler, proje kriterleri olarak tanımlanan PS ve BP'ye ait veriler ise KOSGEB tarafindan belirlenen sayısal değerlere dayanan objektif nicel verilerdir. Anketin ilk bölümünde, kriterlerin karşılaştırılmasında önem dereceleri için 1/9-1-9 Ölçeği (1/9-Mutlak Önemsiz, 1-Eşit, 9-Mutlak Önemli) ve ikinci bölümde destek programlarının kriterler bazında işletmede iyileşme ya da gelişmeye imkan sağlaması konusunda değerlendirilmesi için 1-5 (1-Kesinlikle Katılmıyorum, 5- Kesinlikle katılıyorum) Likert Ölçeği kullanılmıştır. Yanıtlar SPSS 16 programıla değerlendirilmiştir. Her bir bölümün güvenirliği Cronbach$\alpha$ modeli ile test edilmiş ve güvenilirlik düzeyleri 0,60 ile 0,80 arasında, "oldukça güvenilir" bulunmuştur.

\subsection{AHP ile Kriter Ağırlıklarının Belirlenmesi \\ (Determination of Criteria Weights by AHP)}

AHP ile kriter ağırlıklarının belirlenmesi hedeflenmiştir. Anketin ilk bölümünden elde edilen ikili karşılaştırma matrislerinden, birden çok karar vericiye ait sayısal değerler geometrik ortalama kullanılmak suretiyle birleştirilmiş ve tek bir ikili karşılaştırma matrisine dönüştürülmüştür. $\mathrm{Bu}$ matris üzerinde gerçekleştirilen AHP yöntemi adımları ile kriter ağırlıkları büyükten küçüğe sırasıyla; pazarlama $\% 19,9$, Ürün Kalitesi ve Gelișimi \%17,5, Yerli Pazardaki Satışlar \%15,2, Yeni Ürün Dizaynı \% 13,5, Girişimcilik $\% 9,3$, Sanayileşme \%8,5, Bölgesel Gelişim \%7,6, İhracat $\% 5,9$, Proje Süresi \%1,3 ve Proje Bütçesi \%1,2 olarak elde edilmiştir. Her bir matris ve birleştirilmiş ikili karşılaştırma matrisi tutarlı çıkmıştır.

\subsection{PROMETHEE ile Destek Programlarının Siralanması (Ranking Support Programs by PROMETHEE)}

PROMETHEE Yöntemi ile KOBİ'lere sağlanan destek programlarının belirlenen kriterler nazarında önem sıralaması yapılmıştır. Alternatifler "destek programlarından", kriter kümesi ise "örgütsel ve proje performans" kriterlerinden oluşmaktadır. Tercih fonksiyonlarının seçiminde, her bir kriterlere ait sayısal veri ve kriter özelliği dikkate alınmıştır. Kriterler bazında alternatif destek programlarına ait sayısal veriler, anketin ikinci bölümünden elde edilen 1-5 skalasındaki değerlerin aritmetik ortalaması alınarak birleştirilmiş ve Tablo 1'de karar matrisi'nde gösterilmiştir. Karar matrisindeki kriter ağırlıkları AHP yöntemi çıktılarıdır. Standart sapma ve sayısal değer geçişleri dikkate alınarak örgütsel performans kriterleri için VI. Tip Gaussian tercih fonksiyonu seçilmiştir. Proje süresi için birim, aydır. KOSGEB uzmanlarına göre; bir destek programı ile ilgili projenin gerçekleştirilebilmesi için 12 ayın altında proje süresi yeterli değildir. Bunun yanı sıra, projeler için, 36 ay ve üzerinde proje süresi yeterli bulunmaktadır. Bu yüzden proje süresi kriteri için tercih fonksiyonu olarak V. tip uygun görülmüştür. Proje bütçesi kriteri için; KOSGEB uzmanlarınca her bir destek programı için KOBI'lere sağlanacak en az 100000 TL'lik destek yeterli bulunmaktadır. $\mathrm{Bu}$ değerin altında kalan bütçe, KOBI'ler için bir fayda sağlamakta ancak yeterli olamamaktadır. $\mathrm{Bu}$ nedenle; Proje bütçesi kriteri için tercih fonksiyonu olarak III. tip uygun görülmüştür. PROMETHEE-I kısmi sıralama sonuçları Visual-Promethee Yazılımı ile elde edilmiştir. 
Buna göre; en iyi alternatif AGD çıkmıştır. PD, KGD ve IKKD arasında, MTD ile İKD arasında, FD ile İKD arasında, TD ile IKD arasında, FD ile TD arasında ve FD ile DD arasında üstünlük belirlenememiştir. Her bir destek programının pozitif üstünğü $\left(\Phi^{+}\right)$ve negatif üstünlüğü $\left(\Phi^{-}\right)$ ve arasındaki farkı gösteren net üstünlükler $(\Phi)$ hesaplanarak (Tablo 2, 5. sütun), alternatiflerin için tam sıralama Promethee II ile elde edilmiştir. Tablo 2'de net üstünlükler büyükten küçüğe sıralı olarak verilmiştir. Belirtilen sıra, her bir desteğin öncelik sırasını göstermektedir. Buna göre en iyi alternatif ilk sırada yer alan AGD'dir.

Tablo 2. Desteklerin net akış değerleri

(Net flow values of support programs)

\begin{tabular}{lllll}
\hline Sira & Alternatifler & $\Phi^{+}$ & $\Phi^{-}$ & $\Phi$ \\
\hline 1 & AGD & 0,0278 & 0,0046 & 0,0231 \\
2 & KGD & 0,0032 & 0,0154 & 0,0072 \\
3 & PD & 0,0006 & 0,0243 & 0,0070 \\
4 & IKD & 0,0024 & 0,0097 & 0,0052 \\
5 & MTD & 0,0151 & 0,0099 & 0,0042 \\
6 & TD & 0,0139 & 0,0067 & $-0,0035$ \\
7 & FD & 0,0109 & 0,0067 & $-0,0073$ \\
8 & DD & 0,0123 & 0,0054 & $-0,0122$ \\
9 & ED & 0,0063 & 0,0098 & $-0,0237$ \\
\hline
\end{tabular}

4.4. ORESTE ile Destek Programlarının Siralanması (Ranking Support Programs by ORESTE)

ORESTE I Yöntemi 1. Adım için, kriterler için öncelik sırası, AHP yönteminden elde edilen ağırlıklar temel alınarak, \%19,9 ile en büyük ağırlığa sahip P kriteri için "1" Besson sıra değerinden başlamak üzere, \%1,2 ile en küçük ağırlığa sahip PB kriteri için "10" Besson sıra değerini alacak şekilde zayıf sıra değerleri atanmıştır. Alternatif destek programlarının her bir kritere göre önem ilişkisine ait zayıf sıra (Besson sıra) değeri, karar matrisi'ndeki veriler dikkate alınarak hesaplanmış ve Tablo 3'de verilmiştir. Örneğin $\mathrm{G}$ kriteri nazarında, karar matrisinde "3,91" ile en büyük sayısal değere sahip alternatif AGD ve DD ilk iki sırayı paylaştığı için, her ikisinin Besson sıra değeri $((1+2) / 2)=" 1,5$ " olarak hesaplanmıștır (Tablo 3, 2.Sütun, 4 ve 5.Satır). Tablo 1'de G kriteri nazarında " 3,89 " ile PD alternatifi 3.sırada olduğu için " 3 " Besson sıra değerini almıştır (Tablo 3, 2.Sütun, 11.Satır). ORESTE I Yöntemi 2. Adımda, alternatiflerin projeksiyon uzaklık değerleri, Pastijn ve Leysen [20] tarafindan daha güvenilir sonuçlar verdiği belirtildiğinden, doğrusal olmayan projeksiyon formülü $\left(D_{\mathrm{ji}}(\mathrm{a})=\left[\alpha \dot{\alpha}\left(\mathrm{C}_{\mathrm{j}}\right)^{\mathrm{R}}+(1-\alpha) \mathrm{rC}_{\mathrm{j}}(\mathrm{a})^{\mathrm{R}}\right]^{1 / \mathrm{R}}\right)$ ile hesaplanmıştır. doğrusal olmayan projeksiyon formülünde [20]; $D_{j i}$ (a) a alternatifinin mesafesi, $r\left(C_{j}\right)$ j.kriterin Besson sirasını, $\mathrm{rC}_{\mathrm{j}}(\mathrm{a}) \mathrm{j}$.kritere ait a alternatifinin Besson sırasını, $\alpha$ önem derecesini ve $\mathrm{R}$ ise sabit değeri ifade etmektedir. Formülde $\alpha=0,5$ ve $\mathrm{R}=2$ alınmıştır. Örneğin; ilk dört Besson sıra değerine sahip kriter-alternatif pozisyonu şu şekilde hesaplanmıştır: PD Alternatifinin P kriteri bazında projeksiyon uzaklık değeri: $\left[0,5(1)^{2}+0,5(1)^{2}\right]^{0,5}=1$. AGD Alternatifinin Ü kriteri bazında projeksiyon uzaklık değeri: $\left[0,5(2)^{2}+0,5(1)^{2}\right]^{0,5}=$
1,58. İKD Alternatifinin $\mathrm{P}$ kriteri bazında projeksiyon uzaklık değeri: $\left[0,5(1)^{2}+0.5(2,5)^{2}\right]^{0,5}=1,9$. TD Alternatifinin P kriteri bazında projeksiyon uzaklık değeri: $\left[0,5(1)^{2}+0,5(2,5)^{2}\right]^{0,5}=1,9$. ORESTE I Yöntemi 3. Adım için, her bir alternatif için hesaplanan projeksiyon uzaklık değerleri küçükten büyüğe doğru sıralanmış ve bu sıralama dikkate alınarak 1'den 90'a kadar yeni Besson sıra değerleri atanmıştır. İlgili sıra değerleri Tablo 4'de verilmiştir. Daha sonra, her bir alternatif için, toplamda 10 kriter nazarında Besson sira değerleri toplanarak global sıra değerleri Tablo 4 son sütunda elde edilmiştir. Global sıra değerlerine göre, alternatiflerin öncelik sırası PD, AGD, MTD, KGD, TD, FD, DD, IKD ve ED çıkmıştır. Destekleri öne çıkaran kriterler, Besson diziliminde ilk üç sırada yer alan kriterlerdir. Örneğin PD'yi öne çıkaran kriterler; P ve Y kriteridir. Buna göre PD, pazarlama faaliyetlerinde Pazar payı artışında etkili olmaktadır. ORESTE-II ile uyuşmazlık analizi sonucunda, Bir alternatifin diğer alternatife üstün olduğu yani sıralamada önde olduğu kriterlere ait değerlerin fark toplamı tercih üstünlük değerini vermektedir. $\mathrm{Bu}$ değerin, toplam işlem sayısına $\left((\mathrm{n}-1) \mathrm{k}^{2}=(9-1) 10^{2}=800\right)$ bölünmesiyle normalize edilmiş tercih yoğunluğu değeri elde edilir. Örneğin; AGD'nin DD üzerindeki tercih yoğunluğu: $[(18,5-18,5)+(47-23,5)+(28,5-11,0)-(8,0-2,0)$ $+(65,0-9,5)+(76,5-33,0)+(67,0-62,5)+(86,5-79,0)+$ $(89,0-68,0)] / 800=0,22$ şeklinde hesaplanmıştır. Problemin karar matrisi'nde 9 alternatif ve 10 kriter olduğu için eşik değerleri başlık $3.3^{\prime}$ de belirtilen formüller kullanılarak $\quad \beta=0,0125, \quad C^{*}=0,0625, \quad \gamma=0,5 \quad$ olarak hesaplanmıştır. Alternatiflerin tercih yoğunlukları ve eşik değerleri Pastijn ve Leysen [20] tarafından önerilen algoritma adımları izlenerek, tercih-uyuşmazlık matrisi Tablo 5'deki gibi elde edilmiştir. Örneğin; AGD ile PD karşılaştırılamaz çıkmıştır.

\subsection{Elde edilen Stralama Sonuçlarının Özeti ve Destekler İçin Yeni bir Etkinlik Strası Önerisi \\ (Summary of the Obtained Orders and a New Effectiveness Order Suggestion)}

KOBİ performansını etkileyen destek programlarının etki alanlarının farklı olması ve ödünümden kaçınmasından dolay1 PROMETHEE Yöntemi, ve KOBİ performansı değerlendirme sürecinde karar matrisindeki verileri en baştan her bir kriter için sıralama yaparak iki farklı tür kriter grubundaki değerlendirme farklarını ortadan kaldırdığı için ORESTE Yöntemi tercih edilmiştir. Elde edilen sıralama sonuçları Tablo 6'de özetlenmiştir. Tablo 6 'in son sütunun da ise ORESTE-II sonucu oluşan kısmi sıralama temel alınarak tam sıralamaya dönüştürme işi için PROMETHEE-II ile elde edilen tam siralamadan yararlanılarak yeni bir sıralama geliştirme önerisi yapılmıştır. Sıralamada ilk olarak, ORESTE II uyuşmazlık analizi ile elde edilen ilk karşılaştırma yapılamaz alternatif kümesi \{AGD, PD\} ile PROMETHEE-II ile elde edilen tam siralamada ilk sirada yer alan alternatif AGD olması sebebiyle önerilen sırada AGD ilk sırada yer almıştır. Sıralamada ORESTE II uyuşmazlık analizi ile elde edilen ikinci karşılaştırma yapılamaz alternatif kümesi yine $\{$ AGD, PD $\}$ ve PROMETHEE-II ile elde edilen tam siralamada ikinci sırada yer alan alternatif KGD'dir. 
Tablo 3. Alternatiflerin her bir kritere göre ortalama sıra dizisi (Besson ranks of alternatives)

\begin{tabular}{lllllllllll}
\hline Kriterler $\rightarrow$ & G & S & Y & Ü & P & YE & B & I & PS & PB \\
\hline Kriterler için Besson Sıra & 5 & 6 & 3 & 2 & 1 & 4 & 7 & 8 & 9 & 10 \\
$\begin{array}{l}\text { Değerleri } \rightarrow \\
\text { Alternatifler } \downarrow\end{array}$ & & & & & & & & & & \\
AGD & 1,5 & 1 & 3 & 1 & 8 & 1 & 1 & 5 & 6 & 1 \\
DD & 1,5 & 6 & 6 & 3 & 6 & 9 & 8 & 6 & 8 & 8 \\
ED & 8 & 8,5 & 9 & 6,5 & 4 & 7,5 & 9 & 9 & 8 & 9 \\
FD & 6 & 5 & 7 & 8 & 5 & 4 & 5 & 7 & 4,5 & 6 \\
IKD & 9 & 7 & 8 & 9 & 2,5 & 6 & 7 & 8 & 1 & 2 \\
KGD & 4 & 8,5 & 5 & 2 & 7 & 2 & 4 & 1 & 4,5 & 6 \\
MTD & 7 & 2 & 4 & 4,5 & 9 & 3 & 3 & 4 & 2,5 & 3 \\
PD & 3 & 4 & 1,5 & 4,5 & 1 & 5 & 2 & 2 & 2,5 & 4 \\
TD & 5 & 3 & 1,5 & 6,5 & 2,5 & 7,5 & 6 & 3 & 8 & 6 \\
\hline
\end{tabular}

Tablo 4. Yeni sıra değeri atanarak oluşturulan Global Sıra (Global ranks obtained based on new ranking order)

\begin{tabular}{llllllllllll}
\hline & G & S & Y & Ü & P & YE & B & I & PS & PB & $\begin{array}{l}\text { Global } \\
\text { Sira } \\
\text { Değeri }\end{array}$ \\
\hline AGD & 18,5 & 23,5 & 11,0 & 2,0 & 43,0 & 9,5 & 33,0 & 62,5 & 79,0 & 68,0 & 350 \\
DD & 18,5 & 47,0 & 28,5 & 8,0 & 23,5 & 65,0 & 76,5 & 67,0 & 86,5 & 89,0 & 509,5 \\
ED & 62,5 & 73,5 & 64,0 & 30,5 & 9,5 & 48,5 & 81,0 & 86,5 & 86,5 & 90,0 & 632,5 \\
FD & 40,5 & 40,5 & 38,5 & 45,5 & 17,0 & 20,0 & 52,5 & 76,5 & 69,5 & 83,0 & 483,5 \\
IKD & 72,0 & 58,0 & 50,5 & 58,0 & 3,5 & 35,5 & 66,0 & 80,0 & 55,5 & 71,0 & 550 \\
KGD & 26,5 & 73,5 & 21,5 & 5,0 & 33,0 & 12,0 & 43,0 & 43,0 & 69,5 & 83,0 & 410 \\
MTD & 52,5 & 25,0 & 15,5 & 13,5 & 55,5 & 15,5 & 38,5 & 54,0 & 60,5 & 75,0 & 405,5 \\
PD & 21,5 & 35,5 & 6,5 & 13,5 & 1,0 & 26,5 & 37,0 & 45,5 & 60,5 & 78,0 & 325,5 \\
TD & 33,0 & 28,5 & 6,5 & 30,5 & 3,5 & 48,5 & 58,0 & 50,5 & 86,5 & 83,0 & 428,5 \\
\hline
\end{tabular}

Tablo 5. Alternatiflerin tercih-uyuşmazlık matrisi (The final outranking relation matrix)

\begin{tabular}{llllllllll}
\hline & AGD & DD & ED & FD & IKD & KGD & MTD & PD & TD \\
\hline AGD & I & $>$ & $>$ & $>$ & $>$ & $>$ & $>$ & R & $>$ \\
DD & $<$ & I & $>$ & R & R & $<$ & $<$ & $<$ & $<$ \\
ED & $<$ & $<$ & I & $<$ & $<$ & $<$ & $<$ & $<$ & $<$ \\
FD & $<$ & R & $>$ & I & $>$ & $<$ & $<$ & $<$ & $<$ \\
IKD & $<$ & R & $>$ & $<$ & I & $<$ & $<$ & $<$ & $<$ \\
KGD & $<$ & $>$ & $>$ & $>$ & $>$ & I & R & $<$ & R \\
MTD & $<$ & $>$ & $>$ & $>$ & $>$ & R & I & $<$ & R \\
PD & $\mathrm{R}$ & $>$ & $>$ & $>$ & $>$ & $>$ & $>$ & I & $>$ \\
TD & $<$ & $>$ & $>$ & $>$ & $>$ & R & R & $<$ & I \\
\hline
\end{tabular}

Tablo 6. Sıralama özeti ve önerilen sıralama (Ranking order summary and suggested ranking order)

\begin{tabular}{llllll}
\hline Öncelik Sirası & Promethee-I & Promethee-II & Oreste-I & Oreste-II & $\begin{array}{c}\text { Önerilen } \\
\text { Siralama }\end{array}$ \\
\hline 1 & AGD & AGD & PD & AGD, PD & AGD \\
2 & PD, KGD, İKD & KGD & AGD & AGD, PD & PD \\
3 & PD, KGD, İKD & PD & MTD & KGD, MTD, TD & KGD \\
4 & PD, KGD, İKD, MTD & IKD & KGD & KGD, MTD, TD & MTD \\
5 & MTD, IKD & MTD & TD & KGD, MTD, TD & TD \\
6 & FD, TD, İKD & TD & FD & DD, FD & FD \\
7 & FD, TD, IKD & FD & DD & DD, FD, IKD & IKD \\
8 & DD & DD & IKD & DD, IKD & DD \\
9 & ED & ED & ED & ED & ED \\
\hline
\end{tabular}


Bu durumda PD alternatifi, ORESTE II ile karşılaştırma yapılamaz alternatifler kümesinde ilk iki sırada yer alması ve karşılaştırılamaz alternatifi olan AGD'nin de hâlihazırda ilk sıraya yerleştirilmiş olması sebebiyle ikinci sıraya yerleştirilmiştir. Bu noktada PD alternatifinin ORESTE I' de ilk sırada yer alması dikkat çekicidir. Sıralamada ORESTE II uyuşmazlık analizi ile elde edilen üçüncü karşılaştırma yapılamaz alternatif kümesi $\{\mathrm{KGD}$, MTD, TD \} ve PROMETHEE-II ile elde edilen tam siralamada üçüncü sırada yer alan alternatif PD'dir. PD alternatifi hâlihazırda önerilen sıralamada ikinci sırada yerini almıştır. PROMETHEE-II ile elde edilen tam siralamada ikinci sirada yer alan alternatif ise KGD'dir. $\mathrm{Bu}$ durumda karşılaştırılamaz alternatif kümesinde yer alan KGD önerilen sıralamada üçüncü sıraya yerleştirilmiştir. Benzer şekilde ORESTE II uyuşmazlık analizi ile elde edilen karşılaştırma yapılamaz alternatif kümesi, PROMETHEE II ile elde edilen siralama dikkate alınarak yeni öncelik sırası oluşturulmuştur. $\mathrm{Bu}$ önerinin amacı, iki yöntemin faydasının birleştirilerek daha gerçekçi bir sıralama elde etmektir. Yapılan öneride, destek programlarının etkinlik sıralaması oluştururken, karar matrisindeki nicel değerler arasındaki fark karar verici açısından yanıltıcı olabileceği için, ORESTE II temel alınarak bir sıralama oluşturulmuştur. Bir başka ifade ile önerisi yapılan yeni sıralama için, PROMETHEE-II yöntemi tamamlayıc1, ORESTE-II yönteminin ise denetleyici nitelikte kullanılmıştır. Gerek önerilen sıralamada, gerekse PROMETHEE II ve ORESTE I tam siralama sonuç özetlerine göre AGD en etkin ilk üç destek içerisinde yer almaktadır. Ayrıca yine üç sıralamaya göre ED en zayıf destektir. Önerilen sıralama dikkate alındığında KOBİ performansının arttırılmasında en etkin destek en etkin ilk üç destek sırası ile AGD, PD ve KGD'dir.

\section{SONUÇLAR (CONCLUSIONS)}

Bu çalışmada, KOBİ performansına yönelik en etkin destek programlarının belirlenmesi amaçlanmış ve destek programlarının örgütsel performans açısından değerlendirilmesi ele alınmıştır. Destek programları ve performans değerlendirme kriterleri; literatür araştırmasının yanı sıra uzman görüşleri dikkate alınarak titizlikle belirlenmiş ve gerekli veriler istatistiksel güvenilirliği test edilmiş bir anket çalışması ile elde edilmiştir. Gerek yurtdışındaki [12] gerekse ülkemiz KOBI'leri ([11-13]) için literatürde destek programlarına bağlı performans değerlendirme çalışmalarında elde edilen sonuç "destek programının firmaların performansı üzerinde anlamlı etkiler yarattı̆̆ı" şeklindedir. Bu çalışmada ise bir sonraki adım olan, "hangi destek programı öncelikli olarak KOBİ performans1 üzerinde etkindir" sorusu cevaplanmıştır. Günümüzde, ÇKKV alanında farklı yöntemler, çalışmalarda ([25-29]) etkin şekilde kullanılmaktadır. PROMETHEE ve ORESTE yöntemleri bu çalışmada ele alınan problem tanımı gereği en uygun yöntemler olarak seçilmiştir. Bunun başlıca sebebi: Problemde kriter kümesinde yer alan PS ve PB'nin her bir alternatif nazarında aldığı nicel değerler arasındaki büyük farklar (gerek kendi aralarındaki, gerekse sayısal verileri nitel olan diğer kriterlerin 1-5 Likert skala değerleri arasındaki farklılık sebebiyle) karar matrisi kullanan ELECTRE ve TOPSIS gibi diğer ÇKKV yöntemlerinin sonuçlarında büyük etkiye sahip olacaktır. Fakat PROMETHEE, ilgili verileri fayda fonksiyonlarına dönüştürdüğü için bu problemi ortadan kaldırmaktadır. ORESTE Yöntemi de alternatifleri, değerlendirme sürecinin en başında sıralayarak, öncelikleri sıra değerleri ile ifade edilebilir kılmakta ve böylelikle kriterler arasındaki ölçeksel farklılıkları bir dezavantaj olmaktan çıkarması ile bu problemi ortadan kaldırmaktadır. Ayrıca sıralama ya da üstünlük esasına dayanarak karşılaştırma yapılamaz alternatifleri ORESTE-II uyuşmazlık analizi ile belirleyen yöntem, bu çalışmada PROMETHEE ile elde edilen tam sıralamanın denetlenmesi amacıyla kullanılmıştır. Her iki yöntemden elde edilen tam siralamaların yanı sıra, ORESTE-II uyuşmazlık analizi ve PROMETHEE-II tam sıralama sonuçlarının beraberce değerlendirildiği bir bütünleşik yaklaşım ile yeni bir sıralama önerilmiştir [5]. Önerilen yeni sıralamaya göre, KOBİ performansının arttırılmasinda en etkin destekler sirasıyla; AGD, PD ve KGD olmuştur. Söz konusu destekler, KOBİ'lerin gelişiminde; inovasyon, gelişim, kalite, piyasaya yeni ürünlerin kazandırılması, pazar araştırması, tanıtım ve rekabetçilik alanlarına yapılacak olan yatırımların KOBI'lerin performansı için daha etkili olduğunu ortaya koymaktadır. Ayrıca en fazla 3 destek programından yararlanma hakk1 olan KOBİ'lere etkin ve güvenilir fikir verebilmesi açısından sıralamada ilk üçte yer alan desteklerin belirlenmesi kritik bir karar problemine dönüştüğünden, ORESTE-II ve PROMETHEE-II yöntemlerinin sonuçlarının beraberce kullanılması ile etkin bir sıralama elde edilmiştir. Elde edilen sıralama; destekleri sağlayan kuruluşlara da, desteklerin yapısal düzenlemesi ve bütçe planlanması açısından yardımcı olacak niteliktedir. Gelecekte, aynı çalışma, sadece bir bölgede faaliyet gösteren KOBİ'lerle sınırlandırılarak tekrarlanıp bölgesel eğilimler saptamak, ya da, belirli bir sektör dikkate alınarak ilgili sektördeki KOBİ destek programlarının performans etkinliği değerlendirmek hedeflenmektedir. Ayrıca, etkinlik sıralamasında ilk siralarda yer alan desteklerin firmanın performansını ne derecede arttırdığının kısa, orta uzun vadede ölçümü için literatürdeki istatistiksel analiz çalışmalarına benzer bir çalışma geleceğe yönelik bir çalışma olarak değerlendirilebilir.

\section{TEŞEKKÜR (ACKNOWLEDGEMENT)}

Kıymetli kritikleri ile çalışmanın mevcut çalışmalardan farkını ortaya koymamızda bize yol gösteren ve geleceğe yönelik çalışmalar için ilham olan Hakemlere derin teşekkürlerimizi sunarız.

\section{KAYNAKLAR (REFERENCES)}

1. Karabıçak M., Türkiye'de Uygulanan Ekonomik Teşvik Politikalarının Boyutu, Ulusal, Bölgesel ve Yerel Kalkınma Üzerine Olası Etkileri, Süleyman Demirel Üniversitesi İktisadi ve İdari Bilimler Fakültesi Dergisi, 18 (3), 263-280, 2013. 
2. Kalkan, A., KOBI'lere Sağlanan Desteklerin Örgütsel Performansa Etkileri, Doktora Tezi, Gebze Yüksek Teknoloji Enstitüsü, 2005.

3. Tezyetis S., SMEs in Turkey \& vision and support of KOSGEB, PowerPoint Sunumu. KOSGEB.http://www.dps.tesoro.it/cd_cooperazione_bi laterale/docs/4.Study_Visits/2.Study_visit_II_novembe r_2007/3.materials/8.KOSGEB.pdf., Yayın tarihi Kasım 2007. Erişim tarihi Mayıs 27, 2013.

4. Cansiz M., Türkiye'de KOBİ'ler ve KOSGEB, DPT Uzmanlık Tezi, Ankara, 2008.

5. Yerlikaya M.A., KOBI'lere Sağlanan Desteklerin KOBİ Performansına Etkisinin Çok Ölçütlü Karar Verme Yöntemleri ile Değerlendirilmesi, Yüksek Lisans Tezi, Gazi Üniversitesi, Fen Bilimleri Enstitüsü, 2014.

6. Voulgaris F., Doumpos M., Zopounidis C., On the evaluation of Greek industrial SME's performance via multicriteria analysis of financial ratios, Small Business Economics, 15 (2), 127-136, 2000.

7. Vincent C., Lamia B., Gilles M., Deploying the ELECTRE III and MACBETH multicriteria ranking methods for SMEs tactical performance improvements, Journal of Modelling in Management, 8 (3), 351-356, 2006.

8. Ahmad N., Qui R.G. Integrated model of operations effectiveness of small to medium-sized manufacturing enterprises, Journal of Intelligent Manufacturing, 20, 79-89, 2009.

9. Tsai W.H., Chou W.C., Selecting management systems for sustainable development in SMEs: A novel hybrid model based on DEMATEL, ANP, and ZOGP, Expert Systems with Applications, 36 (3), 1444-1458, 2009.

10. Tsai W.H., Kuo H.C., Entrepreneurship policy evaluation and decision analysis for SMEs, Expert Systems with Applications, 38 (4), 8343-8351, 2009.

11. Özcelik E., Taymaz E., R\&D Support Programs in Developing Countries: The Turkish Experience, Research Policy, 37, 258-75, 2008.

12. Maden S., KOSGEB Genel Destek Programının Firmalar Üzerindeki Etkilerinin Değerlendirilmesi: Göller Bölgesi Uygulaması, Doktora Tezi, Süleyman Demirel Üniversitesi, Sosyal Bilimler Enstitüsü, 2012.

13. Erdil O., Kalkan A., Kobilere Sağlanan Desteklerin Kobi Performansına Etkisi, İstanbul Ticaret Üniversitesi Sosyal Bilimler Dergisi, 4 (7), 103-122, 2005.

14. Hwang C.L., Yoon K., Multi Attribute Decision Making Methods and Applications A State of The Art Survey, Springer-Verlag, New York, 253, 1981.

15. Tabucanon M.T., Multiple Criteria Decision Making In Industry, 2nd Edition", Elsevier, New York, 12-107, 1988.
16. Hwang C.L., Lin M.J., Group Decision Making Under Multiple Criteria: Methods and Applications, SpringerVerlag, New York, 1987.

17. Brans J.P., Vincke P., A Preference Ranking Organizastion Method: The PROMETHEE Method for MCDM, Management Science, 31 (3), 647-656, 1985.

18. Figueira J., Greco S., Ehrgott M., Multiple Criteria Decision Analysis: State of the Art Surveys: Edited Book, Springer, Boston USA, 2005.

19. Can Ş. Arikan F., Multi Criteria Subcontractor Selection Problem and its Solution for a Defence Industry Firm, Journal of the Faculty of Engineering and Architecture of Gazi University, 29 (4), 645-654, 2014.

20. Pastjin H., Leysen J., Constructing An Outranking Relation With ORESTE, Math \& Comput. Modelling, 12 (5), 1255-1268, 1989.

21. Saaty $T$., The analytic hierarchy process, McGrawHill International Book Company, USA, 1980.

22. Brans J.P., Vincke P.H., Mareschall B., How to select and how to rank projects: The PROMETHEE method, European Journal of Operational Research, 14 (2), 228-238, 1986.

23. Dağdeviren M., Eraslan E., Supplier Selection Using PROMETHEE Sequencing Method, Journal of the Faculty of Engineering and Architecture of Gazi University, 23 (1), 69-75, 2008.

24. Pastjin H., Leysen J., Using an Ordinal Outranking Method Supporting The Acquisition of Military Equipment, Royal Military Academy Renaissance Avenue, 8 (3), 4-12, 2003.

25. Kul Y., Şeker A., Yurdakul M., Usage of Fuzzy Multi Criteria Decision Making Methods in Selection of Nontraditional Manufacturing Methods, Journal of the Faculty of Engineering and Architecture of Gazi University, 29 (3), 589-603, 2014.

26. Aksakal E., Dağdeviren M., Talent Management Based Personnel Assignment Model and Solution Proposal, Journal of the Faculty of Engineering and Architecture of Gazi University, 30 (2), 249-262, 2015.

27. Karaman B., Çerçioğlu H., 0-1 Goal Programming Aided AHP - VIKOR Integrated Method: an Application of Hospital Investment Project Selection, Journal of the Faculty of Engineering and Architecture of Gazi University, 30 (4), 567-576, 2015.

28. Aydoğan E., Özmen M., Two New Method for Multi Criteria Stochastic Decision Making: SMAA-GRA and SMAA-DEMATEL-GRA, Journal of the Faculty of Engineering and Architecture of Gazi University, 30 (4), 627-640, 2015.

29. Efe B., Efe Ö.F., An Application of Value Analysis for Lean Healthcare Management in an Emergency Department, International Journal of Computational Intelligence Systems, 9 (4), 689-697, 2016. 